\title{
Diversity in breeding sites and distribution of Anopheles mosquitoes in selected urban areas of southern Ghana
}

Precious A. Dzorgbe Mattah ${ }^{1,2^{*}}$, Godfred Futagbi ${ }^{3}$, Leonard K. Amekudzi ${ }^{4}$, Memuna M. Mattah ${ }^{5}$, Dziedzorm K. de Souza ${ }^{6}$, Worlasi D. Kartey-Attipoe ${ }^{6}$, Langbong Bimi ${ }^{3}$ and Michael D. Wilson ${ }^{6}$

\begin{abstract}
Background: Anopheles vectors of malaria are supposedly less common in urban areas as a result of pollution, but there is increasing evidence of their adaptation to organically polluted water bodies. This study characterized the breeding habitats of Anopheles mosquitoes in the two major urban areas in southern Ghana; Accra (AMA) and Sekondi-Takoradi (STMA) Metropolitan Areas, during dry and wet seasons.
\end{abstract}

Methods: Anopheles mosquito larvae were sampled using standard dipping methods to determine larval densities. The origin, nature and stability of 21 randomly selected sites were observed and recorded. Mosquito larvae were reared to adults and Anopheles species identified by both morphological and molecular means.

Results: Sixty-six percent of Anopheles habitats were permanent and 34\% temporal, and 74.5\% man-made while 25. $5 \%$ were natural. Puddles and urban farm sites accounted for over $51 \%$ of all Anopheles mosquitoes sampled. The mean larval densities among the habitat types was highest of 13.7/dip for puddles and lowest of 2.3/dip for stream/river, and the variation between densities were significant $(P=0.002)$. The mean larval densities were significantly higher in the wet season than in the dry season for the two study areas combined $(P=0.0191)$ and AMA $(P=0.0228)$. Over $99 \%$ of the 5,802 morphologically identified Anopheles species were An. gambiae (s.l.) of which more than 99\% of the studied 898 were An. coluzzii (62\%) and An. gambiae (s.s.) (34\%). Urban farms, puddles, swamps and ditches/ dugouts accounted for approximately $70 \%$ of all An. coluzzii identified. Conversely, drains, construction sites, streams/rivers and "others" contributed $80 \%$ of all An. gambiae (s.s.) sampled. The wet season had significantly higher proportion of Anopheles larvae compared to the dry season $(Z=8.3683, P<0.0001)$. Also, the proportion of Anopheles mosquitoes produced by permanent breeding sites was $61.3 \%$ and that of temporary sites was $38.7 \%$.

Conclusion: Taken together, the data suggest that man-made and/ or permanent habitats were the main contributors to Anopheles larval populations in the cities and that regulation of the anthropogenic processes that lead to development of breeding places and proper environmental management can drastically reduce mosquito breeding sites in urban areas of Ghana.

Keywords: Anopheles, Urban, Distribution, Permanent habitat, Temporary habitat, Breeding site

\footnotetext{
* Correspondence: pmattah@ucc.edu.gh; pmattah@yahoo.com

${ }^{1}$ Institute of Environment and Sanitation Studies (IESS), University of Ghana,

Legon, Ghana

${ }^{2}$ Directorate of Academic Planning and Quality Assurance (DAPQA),

University of Cape Coast, Cape Coast, Ghana

Full list of author information is available at the end of the article
} 


\section{Background}

There is a growing interest in urban malaria in subSaharan Africa (SSA). This is because factors which support the prevalence of malaria in urban areas are mainly anthropogenic and are those that promote the continuous presence, breeding and propagation of Anopheles mosquitoes and malaria parasites in the cities [1]. Although increasing surface water pollution caused by rapid urbanization was believed to have hampered the development of Anopheles larvae and eliminate certain species like Anopheles funestus, others such as species of the Anopheles gambiae complex have adapted well and continue to breed even in organically polluted water bodies $[2,3]$. This is contrary to the conventional view that Anopheles mosquitoes breed only in clean or clear water habitats $[4,5]$.

Anopheles mosquitoes exploit varying habitats for breeding. They breed in and around vicinities of deteriorating infrastructure such as broken water pipes, open tins/cans, poorly maintained drains, culverts, market gardens/urban agricultural sites, pools at construction sites, lorry tyre tracks on unpaved roads, low lying areas that are liable to flooding, hydrants, catch pits among others. These are all found close to or in-between houses in the city [6-8]. Most Anopheles mosquito breeding habitats in urban areas are man-made even though natural water habitats are found scattered around the urban milieu [9]. Perceivably, all available landscapes within the city, whether natural or man-made, that collect any form of stagnant water are potential breeding places for mosquitoes and may possibly be habitats for Anopheles mosquitoes. Such habitats are most often maintained in the city by human activities which have underneath it, poor hygiene practices supported by lack of sanitation facilities and poor maintenance culture [10]. Several studies on Anopheles breeding habitats in urban areas of Africa, characterized the breeding places $[3,7,9]$. It has been observed that urbanization could influence the epidemiological characteristics of diseases through the provision of good breeding environment for vectors of infectious diseases [11].

Already, among all the tropical diseases, malaria is considered the most common and devastating especially in SSA. In Ghana, malaria transmission is an all-year round phenomenon with peaks in the rainy seasons, and accounts for between $30-40 \%$ of outpatient visits to health facilities each year [12-14]. In Accra, malaria constitutes $40 \%$ of outpatient visits in most health facilities [15, 16], a higher figure compared to the national average. This study aims at determining habitat preference of Anopheles mosquitoes in Accra and Sekondi-Takoradi municipalities of Ghana. We characterized the breeding places of Anopheles mosquitoes by origin, including man-made or naturally occurring and whether temporary or permanent, in 21 randomly selected points. Natural habitats were considered as naturally occurring, and man-made habitats were those created by anthropogenic activities. Water bodies in which larvae were found at least once and which dried up at least once during the sampling period were classified as temporary. We also defined a permanent habitat as the one in which Anopheles larva were found at least once and contain water throughout the sampling period. Habitat diversity and the types of Anopheles mosquito breeding in these habitats were also studied. In light of the recent reclassification of the $\mathrm{M}$ and $\mathrm{S}$ molecular forms of $A n$. gambiae (s.s.), as An. coluzzii and $A n$. gambiae (s.s.), respectively, it was found necessary to determine their habitat preferences in urban settings.

\section{Methods}

\section{Study areas}

The study was conducted in the two major and the most populous urban areas of coastal Ghana; Accra Metropolitan Area (AMA) and the Sekondi-Takoradi Metropolitan Area (STMA) (Fig. 1). AMA is the national capital and STMA is a regional capital, a harbour city and a hub of activities related to the offshore oil production in the Western Region of Ghana. In 2010, AMA has an approximate population of 1.7 million while that of STMA was 445,205 [17]. The two cities also have and continue to attract migrants from both within and outside the country. Though these two metropolitan areas are in the same ecological zone-coastal savanna zone [17], STMA which is at the western edge of this ecological zone exhibits more characteristics of the rainforest belt and also experience more rainfall than AMA. The climate of southern Ghana is tropical, characterized by two distinctive rainfall seasonsa major one between April and June and a minor one which occurs between September and October. Relative humidity is generally high over $65 \%$.

\section{Selection of sampling sites}

Using the R software 3.0.1 ( $\mathrm{R}$ Core Team, 2012) and ArcGIS (ESRI, Redlands, California, USA) maps of the study areas were divided by an overlaid grid of $2 \mathrm{~km}$ (a homogeneous distance that could cater for land use and land cover changes in urban areas). The grids were converted to point features through the determination of the centroid (central point) of each of the grids. The points were provided with unique numbers and constituted a sampling frame from which $20 \%$ was sampled using the random sample of cases in SPSS version 16 (SPSS Inc Chicago, USA). The final sampled points were georeferenced and their locations (longitudes and latitudes) noted and stored in a GPS for further identification on the field. Where a selected point was not accessible, nearest accessible point was used to replace it. In all, a total of 9 points were sampled out of 44 that 


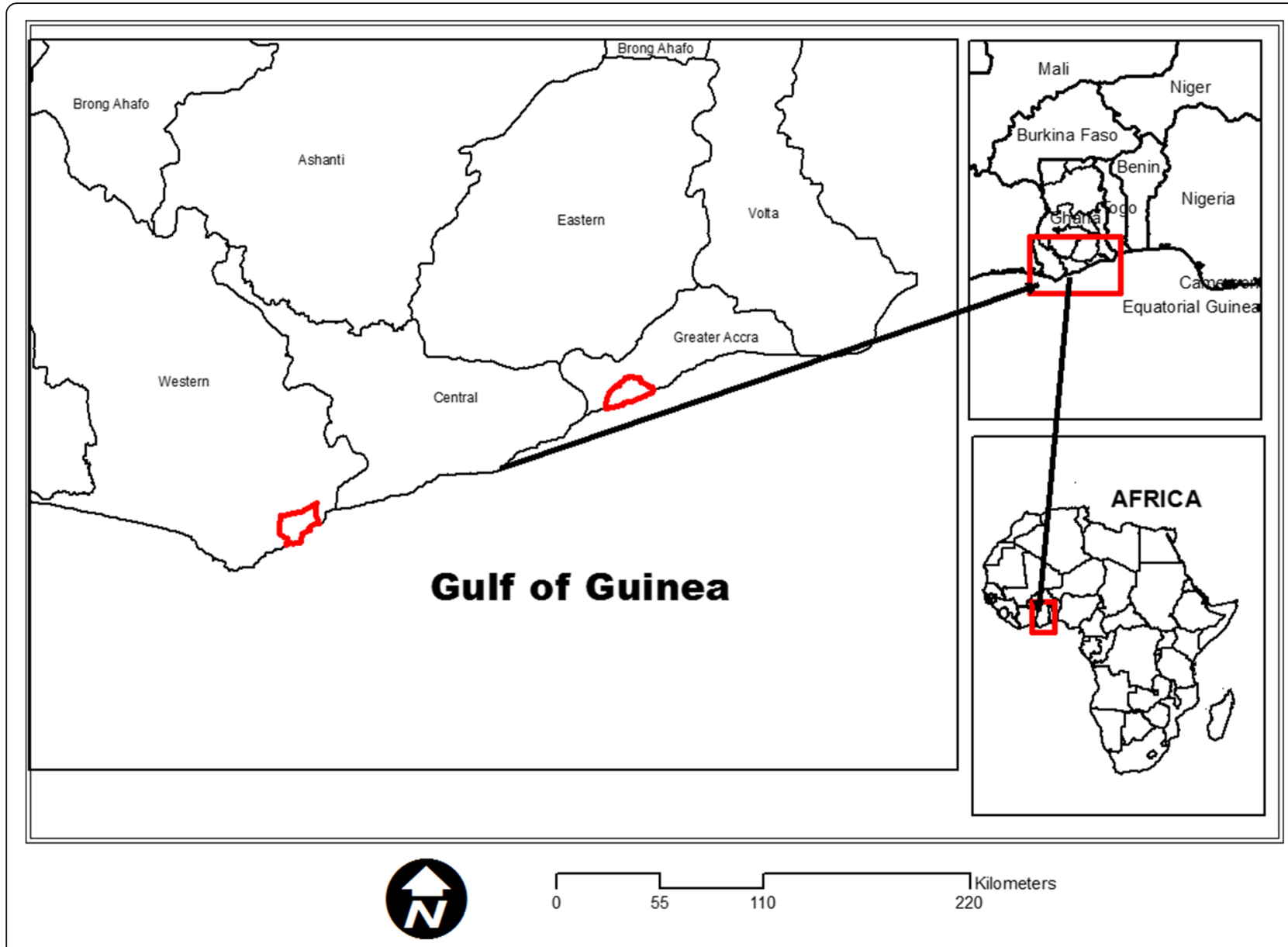

Fig. 1 Location of the study areas in southern Ghana

constituted the sampling frame for AMA and 12 points sampled out of 62 for STMA (Figs. 2 and 3).

\section{Characterization of Anopheles breeding sites}

Habitats of the species were described with respect to whether they were temporary or permanent and man-made or natural.

\section{Anopheles larval sampling}

Before the fieldwork, a reconnaissance survey was conducted during which the sampling points were located on the field using a Garmin GPS navigator (Garmin Inc., Kansas, USA). Identification of Anopheles mosquito breeding sites was achieved through once-a-month larval sampling for 11 consecutive months at the sampling points. Surroundings (within $100 \mathrm{~m}$ radius) of the sampling points were thoroughly searched for possible breeding sites of Anopheles mosquitoes. All identified water bodies likely to harbour mosquito larvae were visually searched thoroughly for the presence of Anopheles mosquito larvae. The presence of Anopheles larvae was determined after 15 dips. Sampling of Anopheles larvae was done using the standard dipping method [18]. A standard dipper $350 \mathrm{ml}$ (Bio Quip Products Inc., Gardena, California, USA) was used. The area of each water body was calculated by walking around the water body (if possible) using a handheld GPS map 62 navigator (Garmin). With large water bodies usually $\left(>10 \mathrm{~m}^{2}\right), 10$ dips per habitat was taken at eight different points. Six dips were taken at 4 different points in small water bodies $\left(<10 \mathrm{~m}^{2}\right)$. For this study, a dip represents a volume of $350 \mathrm{ml}$. Larvae sampled were collected in well-labelled plastic containers (whose covers were perforated to allow for ventilation) and transported to an insectary for rearing to maturity and identification.

\section{Identification of Anopheles mosquitoes}

Larvae brought to the insectary were reared to adults using the methods provided by the Malaria Research and Reference Reagents Resource (MR4) [19]. All adult Anopheles mosquitoes were identified morphologically using the keys of Gillies \& De Meillon [20] and Gillies \& Coetze [21]. 


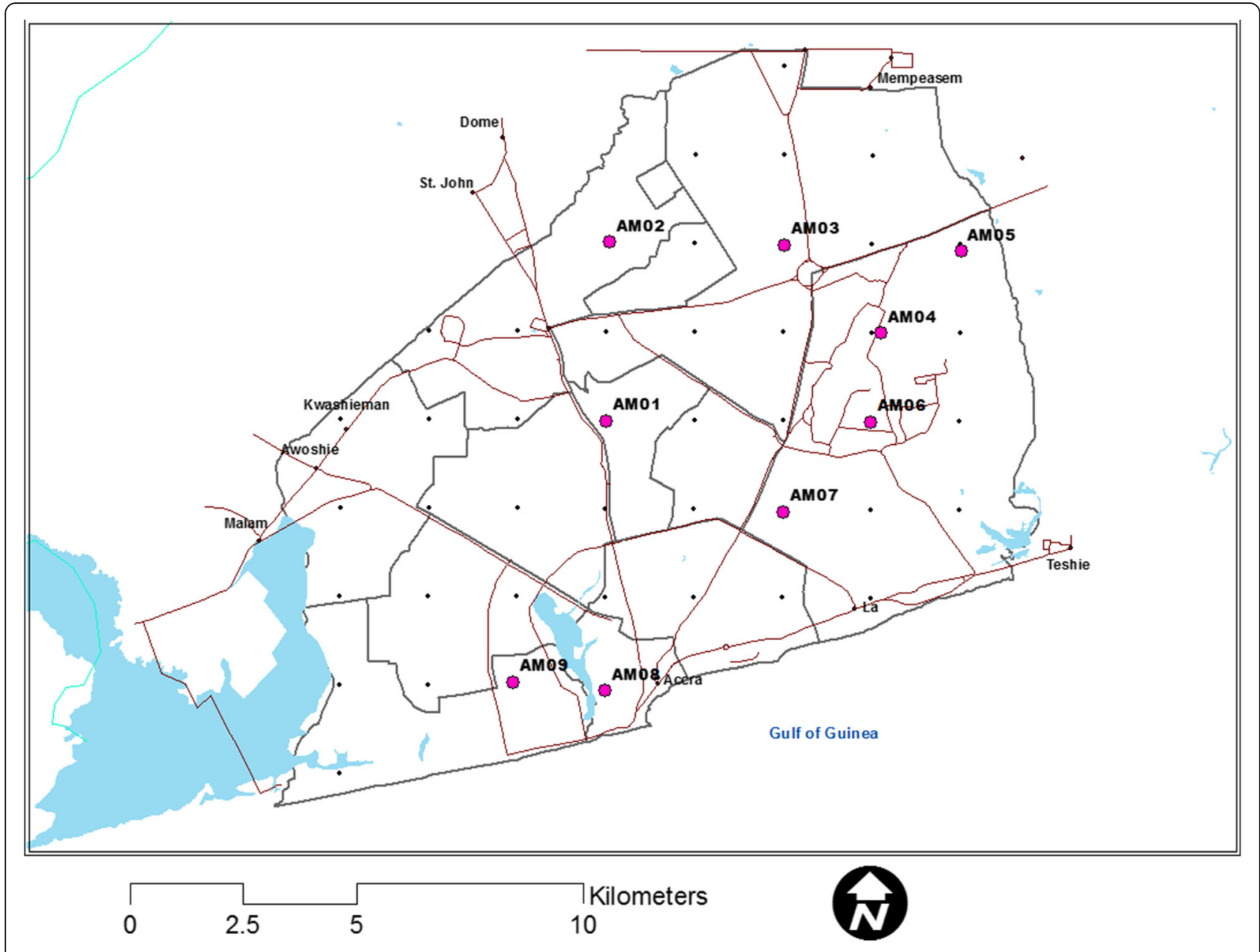

Fig. 2 Sampling points in Accra Metropolitan Area

To identify the sibling species of the Anopheles gambiae complex, genomic DNA of the mosquitoes was extracted using the boiling method [22]. The PCR method proposed by Scott et al. [23] was used to allow for simultaneous identification of the members of Anopheles gambiae complex. With this method, species-specific oligonucleotide primers were used to identify An. gambiae (s.s.), An. melas and $A n$. arabiensis. The primer sequence details and the expected sizes of the PCR products are: Universal (UN) $5^{\prime}$-GTG TGC CCC TTC CTC GAT GT-3' at $56{ }^{\circ} \mathrm{C}$ and 468 bp; An. gambiae (GA) 5 ' -CTG GTT TGG TCG GCA CGT TT-3' at $62^{\circ} \mathrm{C}$ and $390 \mathrm{bp}$; An. melas (ME) 5'-TGA CCA ACC CAC TCC CTT GA-3' at $90{ }^{\circ} \mathrm{C}$ and 464 bp; An. arabiensis (AR) $5^{\prime}$-AAG TGT CCT TCT CCA TCC TA-3' at $78^{\circ} \mathrm{C}$ and $315 \mathrm{bp}$; An. quadrannilatus 5'-CAG ACC AAG ATG GTT AGT AT- 3 ' at $54{ }^{\circ} \mathrm{C}$ and $153 \mathrm{bp}$.

The total volume of PCR reaction mix was $25 \mu \mathrm{l}$, containing $1 \times$ PCR buffer supplied by the manufacturer (Sigma-Aldrich, St. Louis, USA), $20 \mu \mathrm{M}$ deoxyribonucleotide triphosphates (dNTPs), $10 \mu \mathrm{M}$ of each of the four oligonucleotide primers (UN, ME, GA, AR), 0.10 Units of Taq polymerase (Sigma-Aldrich, St. Louis, USA) and $2.5 \mu \mathrm{l}$ of the extracted DNA. Sterile double distilled water was used to make up the volume of $25 \mu \mathrm{l}$. The reaction mix was centrifuged briefly and overlaid with mineral oil to avoid evaporation and refluxing during thermo-cycling. A PTC 100 thermal cycler (MJ Research Inc., Waltham, USA) was used to amplify the DNA. The cycling process involved an initial denaturation at $95^{\circ} \mathrm{C}$ for $10 \mathrm{~min}$, followed by 30 cycles of denaturation at $94{ }^{\circ} \mathrm{C}$ for $30 \mathrm{~s}$, annealing at $50{ }^{\circ} \mathrm{C}$ for $30 \mathrm{~s}$ and extension at $72{ }^{\circ} \mathrm{C}$ for $30 \mathrm{~s}$. A final extension at $72{ }^{\circ} \mathrm{C}$ for $7 \mathrm{~min}$ was performed. For each reaction, negative and positive controls containing no DNA template and a known DNA template were respectively added.

The amplified products were analysed by agarose gel electrophoresis, using $7 \mu \mathrm{l}$ of each PCR product and electrophoresed in $2 \%$ agarose gel stained with $0.5 \mu \mathrm{g} / \mathrm{ml}$ of ethidium bromide (EtBr). The electrophoresis was run in $1 \mathrm{X}$ Tris acetate- EDTA (TAE) buffer at $100 \mathrm{~V}$ for one hour and the gel visualized over a UV transilluminator (Labnet International Inc, Edison, USA). The sizes of the 


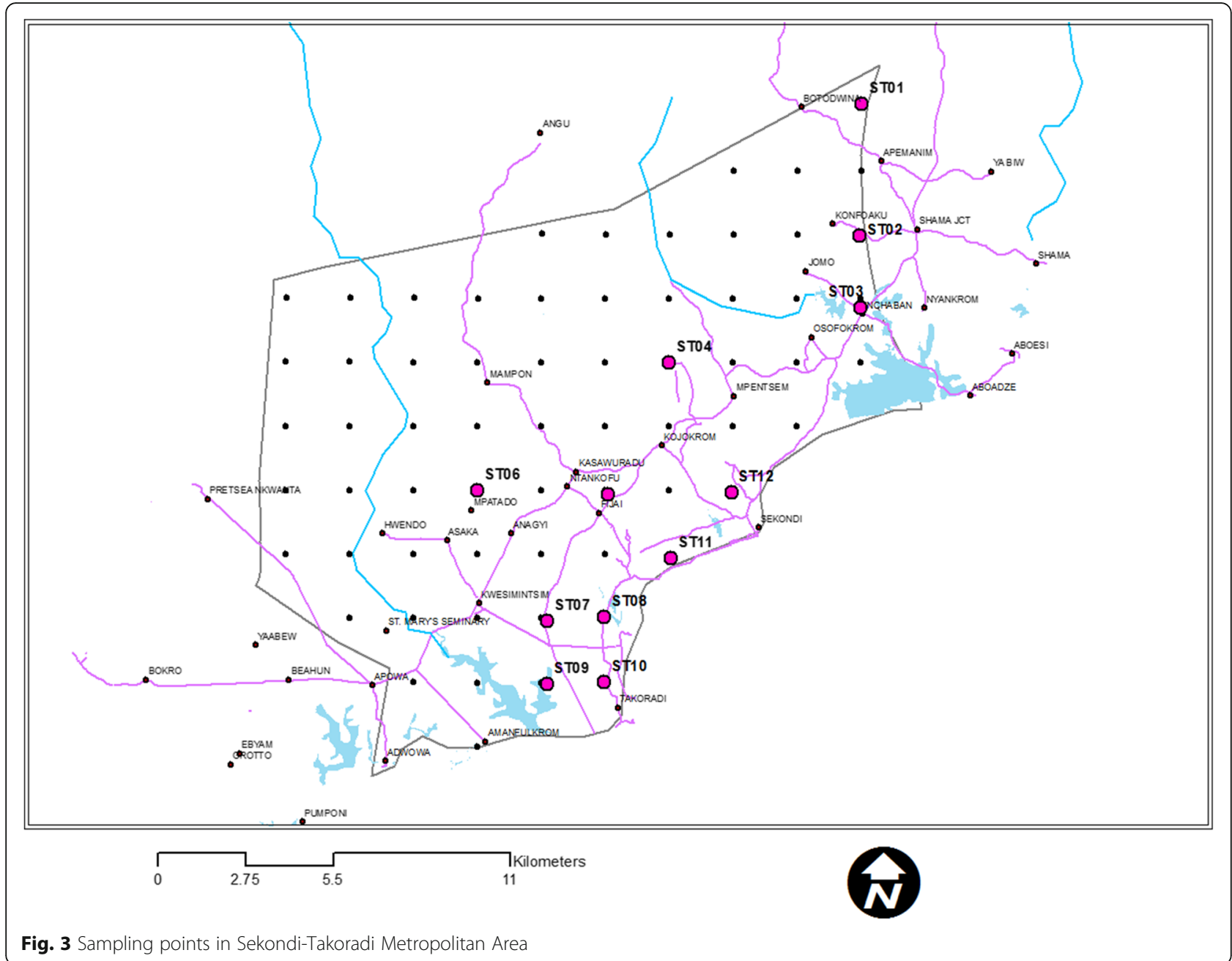

PCR products were estimated by comparison with a 100 bp DNA molecular weight ladder (Biolabs Inc., New England, USA). The separation of Anopheles gambiae (s.s.) from Anopheles coluzzii was done using polymerase chain reaction-restriction fragment length polymorphism (PCR-RFLP) method of Fanello et al. [24]. Ten (10) $\mu \mathrm{l}$ of PCR product was combined with $1 \mathrm{U}$ of Hha1 enzyme (Promega Corporation, Madison, USA) in 10x enzyme buffer (Promega Corporation, Madison, USA).

\section{Statistical analysis}

Data were captured, managed and analysed using the Statistical Package for Social Sciences (SPSS version 16, Inc., Chicago, IL, USA) and Graph Prism Statistical software (Prism, GraphPad Software, San Diego, CA, USA). One-way Analysis of Variance (ANOVA) was used to compare variations in larval densities and counts among habitat types. Pairwise comparisons of larval densities or counts were carried out using Tukey's and Dunnett's tests and $Z$-test for proportions.

\section{Results}

Habitat diversity of sampling areas

Habitat types were characterised in each sampling area. Only one of the 21 sampling points did not have any water body within its $100 \mathrm{~m}$ radius during the sampling period. Water bodies found were grouped into eight different habitat types including puddles, swamps, drains (paved and unpaved), ditches/dugouts, construction sites, urban farm sites, streams/river edges and "others" (lorry tyres and containers). Puddles and paved drains were most common and were both found in eight of the sampling points. Other habitats such as abandoned lorry tyres and containers filled with rainwater were found in five of the sampling points (Table 1 ).

In $80.57 \%$ of 242 visits made throughout the study period, water was found in various habitat types within the $100 \mathrm{~m}$ radius of sampling points. Most, 161 (82.8\%) of 195 habitats were breeding places for different types of mosquitoes. However, Anopheles mosquito larvae were found in 79 (49\%) of the 161 breeding places. In AMA, 46 (66\%) of 70 habitats contained Anopheles mosquitoes 
Table 1 Frequency of habitat types and their contribution to total Anopheles mosquitoes sampled in Accra and Sekondi-Takoradi Metropolitan Areas

\begin{tabular}{lllll}
\hline & \multicolumn{2}{l}{$\begin{array}{l}\text { Frequency at sampling } \\
\text { points } n(\%)\end{array}$} & \multicolumn{2}{l}{ Contribution to total Anopheles mosquitoes sampled (\%) } \\
\cline { 3 - 5 } & $8(19.0)$ & AMA & STMA & ALL \\
\hline Puddles & $4(9.5)$ & 36.9 & 30.6 & 28.6 \\
Swamps & $8(19.0)$ & 1.3 & 11.5 & 13.2 \\
Paved drains & $3(7.1)$ & 12.4 & - & 12.1 \\
Unpaved drains & $4(9.5)$ & 6.2 & 9.3 & 3.7 \\
Ditches/dugouts & $3(7.1)$ & 0.6 & 6.6 & 4.2 \\
Construction sites & $3(7.1)$ & 10.6 & 22.8 & 9.0 \\
Urban farms & $3(7.1)$ & 23.9 & 2.8 & 23.2 \\
Streams/rivers & $5(11.9)$ & 5.0 & - & 4.2 \\
Others & 3.1 & 1.9 & \\
\hline
\end{tabular}

Abbreviations: AMA Accra Metropolitan Area, STMA Sekondi-Takoradi Metropolitan Area

while 48 (38\%) of 125 habitats in STMA had Anopheles mosquitoes. Thus the frequency of seeing a habitat harbouring Anopheles larvae in AMA was higher (1.7 times) than in STMA.

Puddles and urban farm sites in the two cities accounted for more than $51 \%$ of all Anopheles mosquitoes sampled (28.6 and 23.2\%, respectively; Table 1). Habitat types such as old lorry tyres and open containers which were grouped under "others" contributed only $1.9 \%$ of all Anopheles mosquitoes sampled. In AMA, the same two habitats, puddles and urban farm sites, contributed about $61 \%$ ( 36.9 and $23.9 \%$, respectively). The situation was however different in STMA where swamps and urban farm sites contributed approximately 53\% (30.6 and 22.8\%, respectively) to the total Anopheles mosquitoes sampled during the period. Ponds/lagoons had no Anopheles mosquitoes and unpaved drains and "others" were not found in STMA.

\section{Distribution of Anopheles mosquitoes in the study areas}

Five thousand eight hundred and two larvae were reared to adults. Exactly $99.9 \%$ of these were identified morphologically were An. gambiae (s.l.). All Anopheles mosquitoes sampled in AMA were An. gambiae (s.l.) while in
STMA, Anopheles species such as An. coustani (0.06\%) and $A n$. rufipes $(0.05 \%)$ were also found (Table 2$)$.

Using molecular techniques, 898 of the An. gambiae (s.l.) from both cities were further identified as $A n$. coluzzii, An. gambiae (s.s.) and An. melas. Anopheles coluzzii and $A n$. gambiae (s.s.) accounted for $99.8 \%$ of the $A n$. gambiae (s.l.). Only two (0.2\%) of the An. gambiae (s.l.) were identified as $A n$. melas and these species were found only in STMA. Restrictions digest on 896 An. gambiae (s.l.) from all the study areas revealed that An. coluzzii was the majority (62\%) and about $9 \%$ could not be identified after two repetitions of the restrictions digest (Additional file 1). In AMA, there was no significant difference between proportions of $A n$. coluzzii and An. gambiae (s.s.) $(Z=0.7235, P=4694)$. In STMA, however, the proportion of $A n$. coluzzii was significantly and strikingly higher than that of An. gambiae (s.s.) $(Z=41.5392, P<0.0001)$.

\section{Temporal distribution of Anopheles species}

Overall, monthly counts of Anopheles mosquitoes sampled followed a bi-modal trend with peaks in June and October. The two peak months accounted for 15 and $11.8 \%$, respectively, of all Anopheles mosquitoes sampled (Fig. 4). Coincidentally, June and October were periods when

Table 2 Proportions of members of Anopheles gambiae complex identified in Accra and Sekondi-Takoradi Metropolitan Areas

\begin{tabular}{|c|c|c|c|c|}
\hline & & AMA & STMA & ALL \\
\hline & & $n(\%)$ & $n(\%)$ & $n(\%)$ \\
\hline \multirow[t]{3}{*}{ Number of each Anopheles spp. (\%) } & An. rufipes & $0(0)$ & $3(0.14)$ & $3(0.05)$ \\
\hline & An. coustani & $0(0)$ & $4(0.18)$ & $4(0.06)$ \\
\hline & An. gambiae (s.l.) & $3,564(100.00)$ & 2,224 (99.68) & $5,795(99.87)$ \\
\hline \multirow[t]{4}{*}{ Number of each Anopheles (s.l.) members (\%) } & An. melas & $0(0)$ & $2(0.50)$ & $2(0.20)$ \\
\hline & An. coluzzii & $225(43.80)$ & $328(85.86)$ & $553(61.72)$ \\
\hline & An. gambiae (s.s.) & $234(45.50)$ & $24(6.28)$ & $258(28.79)$ \\
\hline & Unidentified & $55(10.70)$ & $30(7.85)$ & $85(9.48)$ \\
\hline
\end{tabular}




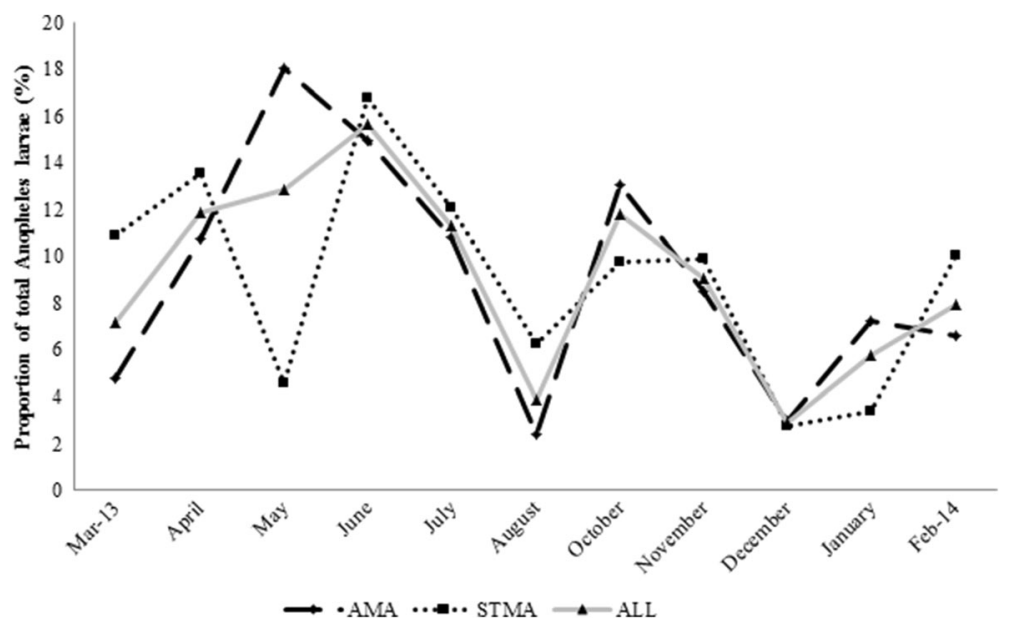

Fig. 4 Monthly distribution in the proportion of Anopheles larvae in Accra (AMA) and Sekondi-Takoradi Metropolitan Areas (STMA). Line ALL indicates monthly distribution of total Anopheles larvae sampled from both cities

high numbers, $14(67 \%)$ and $11(52 \%)$ respectively, of the 21 sampling points had breeding places with larvae. Two dips were observed in the proportion of Anopheles mosquitoes sampled in August (3.9\%) and December (2.9\%) and these also occurred when fewer (28 and $19 \%$, respectively) sampling points had breeding places. A similar trend was observed in AMA with the peak proportions of Anopheles mosquitoes occurring in May $(18 \%)$ and October (13\%). Three dips were also observed in AMA in March, August and December with that of August being the lowest (2.4\%). Monthly distributions in Anopheles larvae sampled in STMA however were characterized with fluctuations with three peaks in April, June and November as well as three dips in May, August and December.
Mean monthly larval density was also characterized with double maxima in the months of June (8.5/dip) and October (7.8/dip) for the entire study areas. Mean monthly larval densities were generally higher for AMA than STMA except for the month of August in which both AMA and STMA recorded an approximate mean of 2.0/dip (Fig. 5). The highest larval density (13.1/dip) for AMA was recorded in May, followed by October (11.4/dip).

The overall monthly distribution of An. coluzzii and An. gambiae (s.s.), in both cities, had An. coluzzii predominating in seven months, including March, April, May, June, July, August and November (Fig. 6). Proportions of An. gambiae (s.s.) were high in the months of October and December, 2013, and January and February, 2014. Even though the population of both species

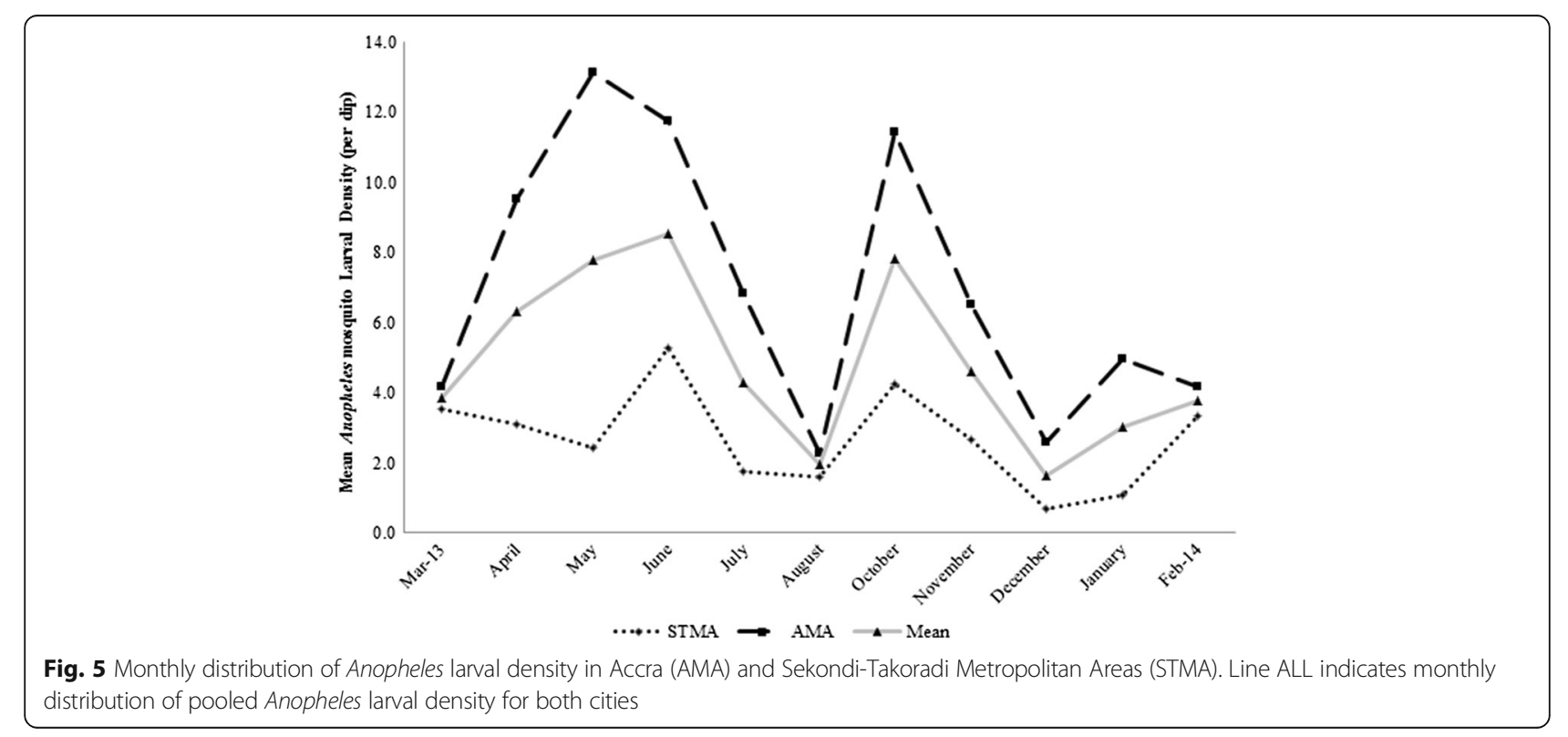




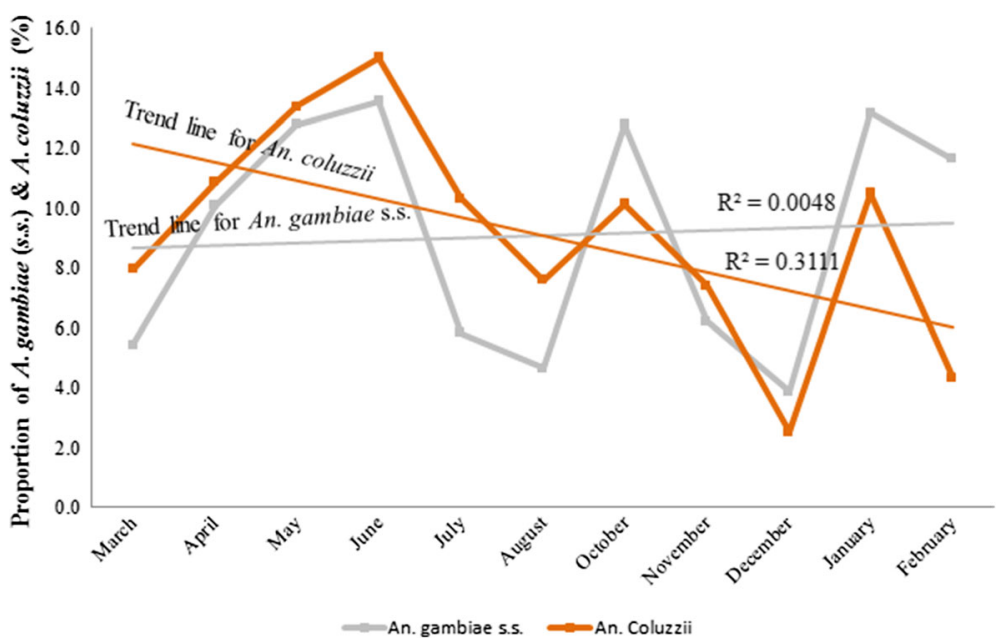

Fig. 6 Monthly distribution of An. coluzzii and An. gambiae (s.s.)

fluctuates throughout the year, An. coluzzii generally declined from March 2013 to February 2014 while An. gambiae (s.s.) increased slightly over the same period.

In Fig. 7, trends vary greatly for both An. coluzzii and An. gambiae (s.s.) when the two cities were examined separately. Generally, in AMA, An. coluzzii and An. gambiae (s.s.) varied throughout the sampling period. However, An. coluzzii were proportionally higher in March, April, May, July and November, compared to An. gambiae (s.s.) while the An.gambiae (s.s.) were proportionally higher in June, August, October, December, 2013, and January and February, 2014 compared to the An. coluzzii. In STMA, while the An. gambiae (s.s.) fluctuates greatly with high peaks in April and October, the An. coluzzii predominated in March, May, June, July, August, December, 2013 and January, 2014. An. gambiae (s.s.) were absent in May, August, December, 2013 and January, 2014. Comparing An. coluzzii of AMA and STMA showed that An. coluzzii were more abundant in AMA only in the months of April,
May and December, 2013, while it was more abundant in months of June, July, August, October, November, 2013 and February, 2014 in STMA. Whenever An. gambiae (s.s.) of AMA increased, An. gambiae (s.s.) of STMA decreased. The STMA's An. gambiae (s.s.) also has wide variations with the highest peaks in April and October.

Seasonal variations were also observed in the population of total Anopheles larvae sampled. As expected, the wet season had significantly higher proportion of Anopheles larvae compared to the dry season $(Z=8.3683, P<0.0001)$, accounting for over $60 \%$ of all Anopheles mosquito larvae sampled from the two cities. Likewise, significantly higher proportions of larvae were observed in the wet season compared to the dry season in AMA $(Z=3.5859, P=$ $0.0003)$ and STMA $(Z=3.0641, P=0.0022)$ (Table 3). Similar to the larval population, mean larval densities were significantly higher in the wet season compared to the dry season for combined study areas $\left(\mathrm{t}_{(161)}=2.367, P=0.0191\right)$ and AMA $\mathrm{t}_{(75)}=2.324, P=0.0228$ ) (Table 3$)$. However, in

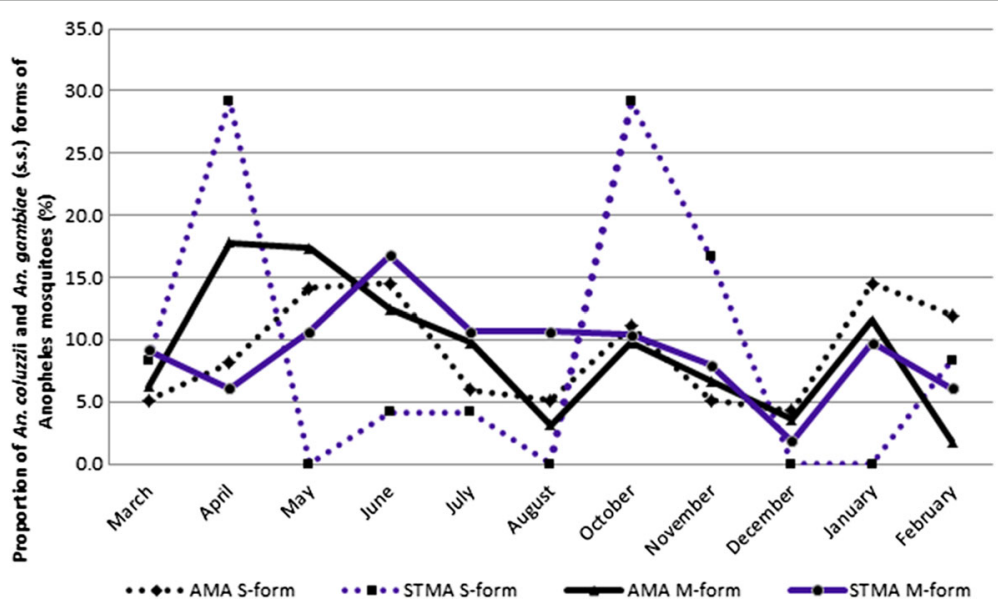

Fig. 7 Monthly distribution of An. coluzzii and An. gambiae (s.s.) in Accra and Sekondi-Takoradi Metropolitan Areas 
Table 3 Proportion and density of larvae compared between wet and dry seasons in Accra and Sekondi-Takoradi Metropolitan Areas

\begin{tabular}{lllll}
\hline & Season & AMA & STMA & ALL \\
\hline \% of total Anopheles larvae (number of habitats sampled) & Wet & $69.2(26)$ & $62.2(30)$ & $37.8(18)$ \\
& Dry & $30.8(20)$ & $36.4(56)$ \\
Mean larval density (per dip) & Wet & $9.2 \pm 1.7$ & $3.1 \pm 0.6$ & $6.1 \pm 0.9$ \\
& Dry & $4.2 \pm 1.1$ & $2.1 \pm 0.6$ & $3.1 \pm 0.6$ \\
\hline
\end{tabular}

Abbreviations: AMA Accra Metropolitan Area, STMA Sekondi-Takoradi Metropolitan Area

STMA, though mean larval density was higher in the wet season compared to the dry season, it was not significant $\left.\mathrm{t}_{(108)}=1.141, P=0.2562\right)$.

\section{Spatial distribution of Anopheles species}

Analysis of variance showed that the mean larval densities varied significantly among habitat types (ANOVA: $\left.F_{(8,89)}=3.384, P=0.0020\right)$ with puddles (13.7/dip) having the highest and stream/river the lowest (2.3/dip) (Fig. 8). Separate focus on each city showed similar significant variations in mean larval densities among habitat types in AMA (ANOVA: $F_{(8,44)}=2.987, P=0.0063$ ) (Fig. 9). Though significant variations existed among the habitat types in STMA (ANOVA: $F_{(6,39)}=2.555, P=0.0342$ ), it was due to low larval density of streams/rivers (1.5/dip), which was significantly lower as compared to the rest of the habitat types (all $P<0.05$ ). No significant differences were found among the rest of the habitat types in STMA. Comparing AMA to STMA, showed that larval densities of habitat types in AMA were generally higher than those of STMA. Puddles and urban farm sites in AMA had significantly higher larval densities compared to the same habitats in STMA $\left(t_{(19)}=2.224, P=0.0385\right.$ and $t_{(13)}=2.378, P=0.0109$, respectively).

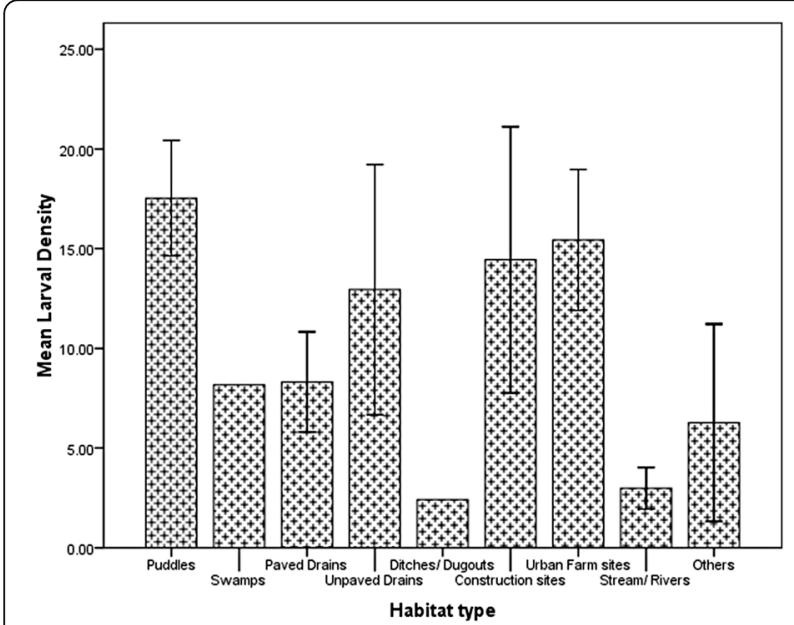

Fig. 8 Habitat and larval density in the two study areas combined. The bars represent the mean larval density for habitat types found in the two cities. Error bars are the standard errors of the means
Significant variations were also observed in $A n$. coluzzii and $A n$. gambiae (s.s.) mean counts among the habitat types in both AMA and STMA $(P<0.05)$. Comparing the counts of $A n$. coluzzii between AMA and STMA revealed that apart from puddles and urban farm sites, the rest of the habitat types in STMA had higher mean numbers compared to AMA (Fig. 10a,c). Conversely, An. gambiae (s.s.) mean counts were generally and interestingly higher in AMA compared to STMA (Fig. 10b,d). Additionally, puddles and urban farm sites that had higher mean numbers of $A n$. coluzzii compared to the rest of the habitats had the lowest An. gambiae (s.s.) numbers in AMA (Fig. 10a,b). Four habitats including urban farms, puddles, swamps and ditches/ dugouts contributed approximately $70 \%$ of all An. coluzzii identified in the entire study whereas drains (paved and unpaved), construction sites, streams/rivers and "others" contributed $80 \%$ of all $A n$. gambiae (s.s.) sampled in the two cities (Fig. 10e,f).

\section{Nature, origin and stability of habitats}

Anopheles breeding sources were grouped as temporary and permanent. Overall, the analysis revealed that 62 (66\%) of the 94 Anopheles habitats were permanent, when the two cities were combined. Similarly, sixty-five percent $(65 \%)$ of all habitats found in AMA were permanent types (Table 4). These include puddles (19.6\%), paved drains (15.2\%), ditches/dugouts (2.2\%), urban farms (13.0\%) and streams/rivers (15.2\%). All paved drains, ditches/ dugouts and streams/ rivers, were permanent habitats in AMA. However, unpaved drains, construction sites, swamps and "others" were all temporary in AMA. These habitats also constituted 2.2, 6.5, 6.5 and 6.5\% respectively of all the temporary habitats in AMA. Most of the puddles (69\%) and urban farm sites (75\%) were permanent habitats in AMA.

In STMA, $66.7 \%$ of the habitats sampled were permanent (Table 5). These were swamps $(25.0 \%)$, paved drains (8.3\%), ditches/dugouts (4.2\%), construction sites $(8.3 \%)$, urban farm sites (10.4\%) and streams/rivers (10.4\%). All construction sites and stream/ rivers were permanent habitats in STMA. Puddles found in STMA were all temporary and constituted about $15 \%$ of total habitats for STMA. Ditches/ dugouts in STMA were split 


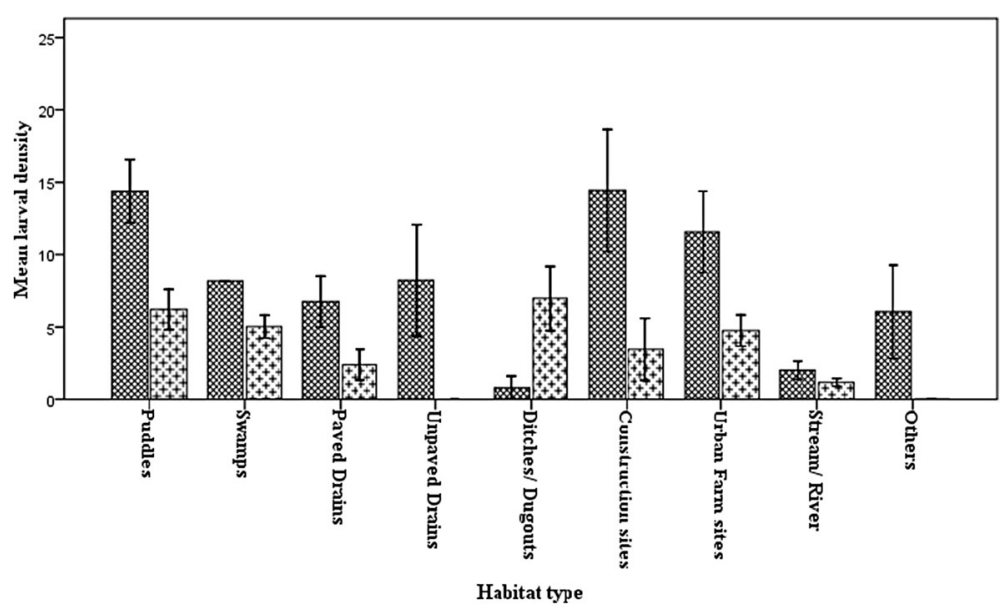

Fig. 9 Habitat and larval density compared between Accra (AMA) and Sekondi- Takoradi Metropolitan Areas (STMA). The dark bars with square designs represent mean larval densities for Accra Metropolitan Area, the light bars with 'plus' signs indicate the mean larval density for SekondiTakoradi Metropolitan Area. Error bars are the standard errors of the means

equally $50 \%$ temporary and $50 \%$ permanent whereas paved drains were $43 \%$ temporary and $57 \%$ permanent.

The origin of Anopheles habitats was grouped into either natural or man-made. Overall, $70(74.5 \%)$ of the 94 Anopheles mosquito habitats found were man-made and the remaining $25.5 \%$ were natural. About $80 \%$ of the habitats found in AMA were man-made and the rest natural. All stream/river habitats were naturally occurring
Anopheles breeding places in AMA. In STMA, 69\% of Anopheles habitats were man-made. Indeed, habitats such as puddles, paved drains, ditches/dugouts, construction sites and urban farm sites all owed their origin to human activities.

In terms of proportions, Anopheles mosquitoes produced by permanent breeding sites were $61.3 \%$ and that of temporary sites was $38.7 \%$ for all the two cities combined.

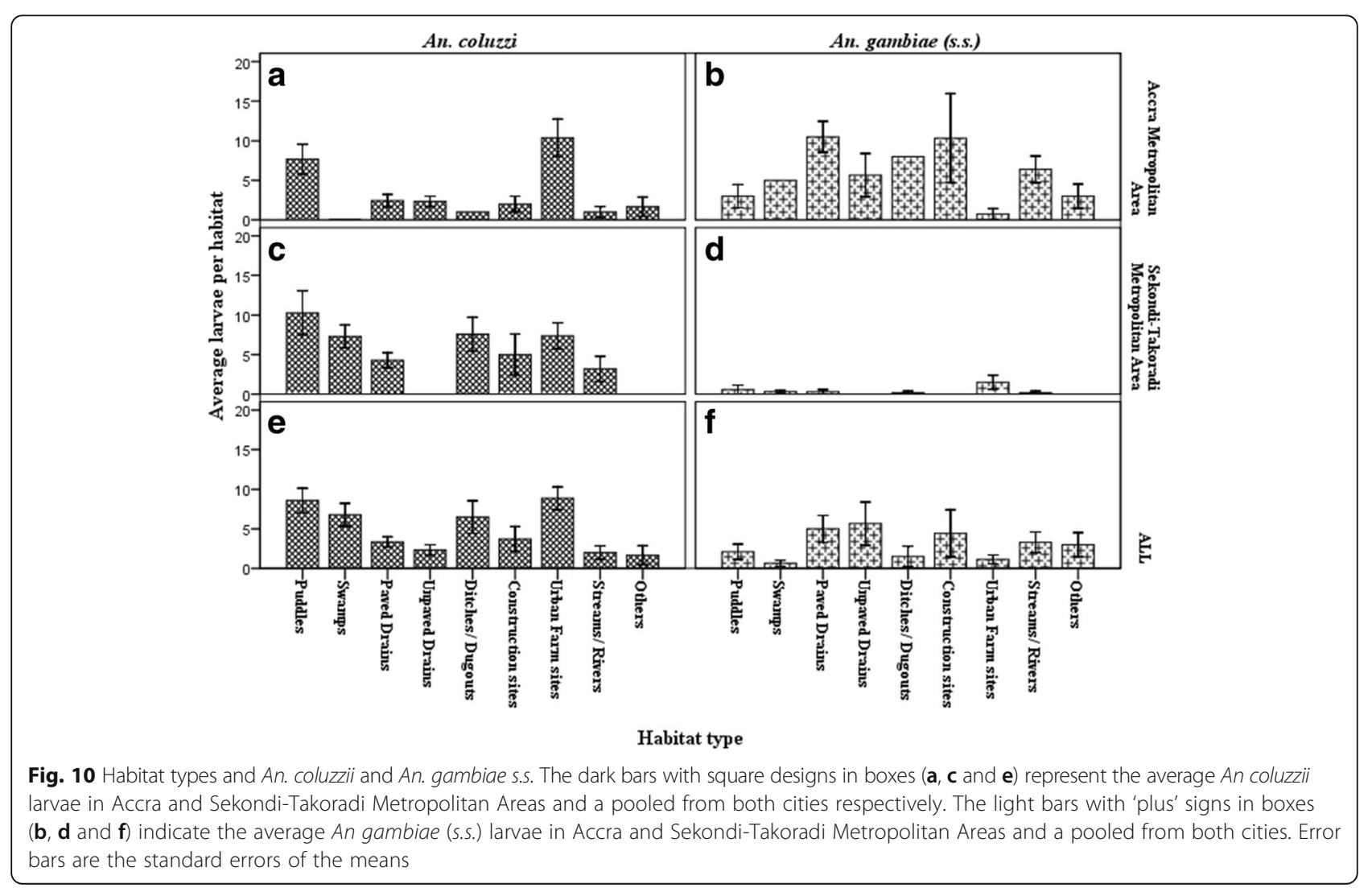


Table 4 Nature and origin of Anopheles mosquito habitats in Accra Metropolitan Area

\begin{tabular}{|c|c|c|c|c|}
\hline \multirow[t]{3}{*}{ Habitat type } & \multicolumn{2}{|c|}{ Nature of site } & \multicolumn{2}{|c|}{ Origin of site } \\
\hline & Temporary & Permanent & Natural & Man-made \\
\hline & $n(\%)$ & $n(\%)$ & $n(\%)$ & $n(\%)$ \\
\hline \multirow[t]{2}{*}{ Puddles } & $4(30.8)$ & $9(69.2)$ & $0(0)$ & $14(100)$ \\
\hline & 8.7 & 19.6 & 0 & 30.4 \\
\hline \multirow[t]{2}{*}{ Swamps } & $1(100)$ & $0(0)$ & $0(0)$ & $0(0)$ \\
\hline & 2.2 & 0 & 0 & 0 \\
\hline \multirow[t]{2}{*}{ Paved drains } & $0(0)$ & $7(100)$ & $0(0)$ & $7(100)$ \\
\hline & 0 & 15.2 & 0 & 15.2 \\
\hline \multirow[t]{2}{*}{ Unpaved drains } & $3(100)$ & $0(0)$ & $0(0)$ & $3(100)$ \\
\hline & 6.5 & 0 & 0 & 6.5 \\
\hline \multirow[t]{2}{*}{ Ditches/ Dugouts } & $0(0)$ & $1(100)$ & $0(0)$ & $1(100)$ \\
\hline & 0 & 2.2 & 0 & 2.2 \\
\hline \multirow[t]{2}{*}{ Construction sites } & $3(100)$ & $0(0)$ & $0(0)$ & $3(100)$ \\
\hline & 6.5 & 0 & 0 & 6.5 \\
\hline \multirow[t]{2}{*}{ Urban farm sites } & $2(25.0)$ & $6(75.0)$ & $2(25.0)$ & $6(75.0)$ \\
\hline & 4.3 & 13.0 & 4.3 & 13.0 \\
\hline \multirow[t]{2}{*}{ Stream/ River beds } & $0(0)$ & $7(100)$ & $7(100)$ & $0(0)$ \\
\hline & 0 & 15.2 & 15.2 & 0 \\
\hline \multirow[t]{2}{*}{ Other } & $3(100)$ & $0(0)$ & $0(0)$ & $3(100)$ \\
\hline & 6.5 & 0 & 0 & 6.5 \\
\hline No. of habitats $(n=46)$ & 16 & 30 & 9 & 37 \\
\hline$\%$ of total & 34.8 & 65.2 & 19.6 & 80.4 \\
\hline
\end{tabular}

Table 5 Nature and origin of Anopheles mosquito habitats in Sekondi-Takoradi Metropolitan Area

\begin{tabular}{|c|c|c|c|c|}
\hline \multirow[t]{3}{*}{ Habitat type } & \multicolumn{2}{|c|}{ Nature of site } & \multicolumn{2}{|c|}{ Origin of site } \\
\hline & Temporary & Permanent & Natural & Man-made \\
\hline & $n(\%)$ & $n(\%)$ & $n(\%)$ & $n(\%)$ \\
\hline \multirow[t]{2}{*}{ Puddles } & $7(100)$ & $0(0)$ & $0(0)$ & $7(100)$ \\
\hline & 14.6 & 0 & 0 & 14.6 \\
\hline \multirow[t]{2}{*}{ Swamps } & $1(7.7)$ & $12(92.3)$ & $10(76.9)$ & $3(23.1)$ \\
\hline & 2.1 & 25.0 & 20.8 & 6.2 \\
\hline \multirow[t]{2}{*}{ Paved drains } & $3(42.9)$ & $4(57.1)$ & $0(0)$ & $7(100)$ \\
\hline & 6.2 & 8.3 & 0 & 14.6 \\
\hline \multirow[t]{2}{*}{ Ditches/ Dugouts } & $2(50.0)$ & $2(50.0)$ & $0(0)$ & $4(100)$ \\
\hline & 4.2 & 4.2 & 0 & 8.3 \\
\hline \multirow[t]{2}{*}{ Construction sites } & $0(0)$ & $4(100)$ & $0(0)$ & $4(100)$ \\
\hline & 0 & 8.3 & 0 & 8.3 \\
\hline \multirow[t]{2}{*}{ Urban farm sites } & $3(37.5)$ & $5(62.5)$ & $0(0)$ & $8(100)$ \\
\hline & 6.2 & 10.4 & 0 & 16.7 \\
\hline \multirow[t]{2}{*}{ Stream/ River beds } & $0(0)$ & $5(100)$ & $5(100)$ & $0(0)$ \\
\hline & 0 & 10.4 & 10.4 & 0 \\
\hline No. of habitats $(n=48)$ & 16 & 32 & 15 & 33 \\
\hline$\%$ of total & 33.3 & 66.7 & 31.2 & 68.8 \\
\hline
\end{tabular}

In AMA, permanent breeding sites yielded $57.4 \%$ and the temporary sites had $42.6 \%$ of all Anopheles sampled in the city. In the case of STMA, permanent sites had $65 \%$ while temporary sites gave $35 \%$ of Anopheles mosquitoes sampled.

When the origin and nature of habitats were combined, further analysis revealed that $39(55.7 \%)$ of the 70 manmade Anopheles habitats were permanent while 31 (44.3\%) were temporary sites. Also 23 (95.8\%) of the 24 natural Anopheles habitats were permanent with the remaining 1 (4.2\%) being temporary habitats overall. In AMA, 21 (56.8\%) of the 37 man-made habitats were permanent while $16(43.2 \%)$ were temporary and all $9(100 \%)$ of the natural habitats were permanent. Likewise, in STMA, 18 (54.5\%) of 33 man-made habitats were permanent while 15 (45.5\%) were temporary and 14 (93.3\%) of 15 natural habitats were permanent with remaining 1 (6.7\%) being temporary. In both cities, majority of the habitats were permanent and man-made.

\section{Discussion}

Although about $83 \%$ of habitats identified were breeding places for different types of mosquitoes, Anopheles mosquito larvae were found in only $49 \%$ of them and the frequency of seeing a habitat harbouring Anopheles larvae in AMA was 1.7 times higher than in STMA. These variations may be due to the differences in the quality of water, that is, the physical, chemical and biological compositions of the water in the various habitats [25-27].

The data also revealed that Anopheles mosquito habitats were very diverse in the two cities. The diversity of the habitats is obviously due to the improper execution of developmental projects, lack of maintenance and poor environmental management that characterize many cities in developing countries. This is not the first time habitat types such as puddles, swamps, ditches/ dugouts, construction sites, urban farm sites, streams/ river edges and ponds/lagoons had been identified, other researchers had found them in urban areas $[8,28]$. The two most common Anopheles mosquito habitat types found in this study were puddles (19\%) and paved drains (19\%) and this corroborates the earlier findings of De Silva \& Marshall [29].

Puddles and urban farm sites in the two cities accounted for more than $51 \%$ of all Anopheles mosquitoes sampled and in AMA, the two habitats contributed a little over 60\% of all Anopheles mosquitoes sampled. In STMA, however, swamps and urban farm sites were the highest contributors to Anopheles mosquitoes sampled in the city, accounting for approximately 53\%. This indicates that eradicating puddles, and destroying breeding sites around urban farm sites and swamps can significantly reduce the population of Anopheles mosquitoes in the two cities. 
Mosquito habitats have been classified as permanent and temporary. Grouping the habitats into temporary and permanent sites helps in understanding the stability of the breeding sites and for that matter, the extent to which each site contributes to the population of Anopheles mosquitoes in the study areas [30]. Temporary sites were mainly rain-dependent and dried up when it had not rained for a while. Permanent sites on the other hand, had a regular source of water either from underground as was in the case of certain low and marshy areas, rivers/streams or broken pipes which normally support puddles, as found also by Imbahale et al. [30] and Mereta et al. [31]. These mean whereas permanent habitats continuously support the breeding of Anopheles mosquitoes, breeding in temporary habitats is curtailed when they dry up due to intermittent supply of water. About 65 and $67 \%$ of habitats found in AMA and STMA, respectively, were permanent and as a result, $66 \%$ of all the habitats identified in the two cities put together were permanent. This explains why malaria transmission in cities is perennial [32]. Anopheles mosquito habitats were also classified by their origin. The data revealed that $74.5 \%$ of the habitats were man-made and the rest natural. Also, over 80 and $69 \%$ of the habitats in AMA and STMA, respectively, were man-made. These indicate that intense human activities in the urban milieu are creating breeding places for the Anopheles mosquitoes and are, therefore, major factors in malaria transmission. Interestingly, the data showed that more than half of the man-made habitats were permanent (55.7\%) and the trend is the same for both cities. Though this is lower than what was observed in Kenya, where man-made habitats constituted about $95 \%$ of the breeding sources encountered $[29,33]$, it is still high. One reason why paved drains, puddles, ditches/dugouts were permanent breeding sites was that nobody attempted to clean the areas, repair broken pipes, remove debris from choked drains or fill the dugouts at construction sites that created those habitats. For example, a broken pipe that resulted in a puddle had been left unrepaired throughout the sampling period at one of the sampling point in AMA. Also a paved drain that had been clogged with debris in another sampling point in AMA was also left unattended to throughout the sampling period. In both AMA and STMA, numerous ditches/ dugouts produced by individuals, private companies and government agencies had all been left unattended to throughout the sampling period. These data support the suggestion that urban malaria is largely manmade [34] and can be reduced just by everybody doing the right thing.

Contrary to the findings of Khaemba et al. [33], Keating et al. [28] and Mereta et al. [31] showing that proportions of Anopheles mosquitoes produced by permanent sites were less than those of temporary sites, in this study higher proportion (61.3\%) of Anopheles mosquitoes were found in permanent sites of the two study areas. The proportion is even higher $(65 \%)$ in permanent sites of STMA than that of AMA (57.4\%). This corroborates the findings of De Silva \& Marshall [29] showing that Anopheles mosquitoes were most likely to be found in permanent shallow sunlit pools than temporary sites because the latter may not provide sufficient time for the maturation of Anopheles mosquitoes from eggs to adults. The implication is that malaria transmission would no longer be seasonal as observed by De Castro et al. [35] and Dery et al. [36] but perennial. It is also worth mentioning that on certain occasions and depending on the volume of water, permanent sites may either get too polluted or get flushed by heavy downpour and hence be rid of Anopheles larvae [37].

Over 99\% of Anopheles mosquitoes sampled were morphologically identified as An. gambiae complex for the two cities combined, just as was found by [8] in AMA. Other Anopheles species such as An. coustani and $A n$. rufipes were very rare and found only in STMA. It is known that $A n$. gambiae complex is the dominant Anopheles species in Ghana [38] and this study has confirmed that. Similarly, almost all the members of the $A n$. gambiae complex analysed were $A n$. coluzzii and $A n$. gambiae (s.s.) (together constituting over 99\%) with only 0.2\% being An. melas. Again, the few An. melas observed were found in STMA only. Additionally, members of the An. gambiae complex in AMA were made up of similar proportions of $A n$. coluzzii and An. gambiae (s.s.). These are not different from what others had found. An. coluzzii and An. gambiae (s.s.) have been reported as the most dominant species in Ghana and were the only members of the Anopheles gambiae complex in AMA [8, 39, 40]. The predominance of $A n$. coluzzii and An. gambiae (s.s.) in Ghana is not surprising because they have been reported as the most widespread of all the malariatransmitting mosquitoes in sub-Saharan Africa [41, 42].

The overall data showed predominance of $A n$. coluzzii (62\%) over the An. gambiae (s.s.) (29\%) and STMA had an overwhelming prevalence of the An. coluzzii (86\%), which is significantly higher than that of $A n$. gambiae (s.s.). This agrees with the findings that suggest that $A n$. coluzzii is more prevalent in savannah areas as compared to An. gambiae (s.s.) which is more dominant in forest zones [39, 43-45]. However, AMA had almost equal proportion of the An. coluzzii (44\%) and An. gambiae (s.s.) (46\%). Higher proportion of An. gambiae (s.s.) was found in similar studies in AMA [8, 46]. On the contrary, Kabula et al. [40] found more An. coluzzii than An. gambiae (s.s.) in AMA. There are, therefore, some variations in the reports of the proportions of $A n$. coluzzii and An. gambiae (s.s.) in AMA and in the entire southern Ghana. This was also observed by Clarkson et al. [47] in mapping the frequencies of An. coluzzii and An. gambiae (s.s.) in southern Ghana. These variations 
can be attributed to the particular areas where sampling was done. For example, samples taken from Korle-Bu for this study, that of Achondu et al. [47] and Klinkernberg et al. [8] all had higher proportions of An. coluzzii than An. gambiae (s.s.) and all samples collected from Airport area by these same authors had more An. gambiae (s.s.) than An. coluzzii. However, samples taken by Kabula et al. [40] from Korle-Bu, Legon and Madina yielded $56.46 \%$ of An. coluzzii and $43.54 \%$ of An. gambiae (s.s.).

Temporal distribution of Anopheles mosquitoes showed that both larval counts and density were high in June and October with dips in August and December. The data suggest that larval counts and density of Anopheles mosquitoes not only increase but also their breeding places increase tremendously during rainy months of the year. This is also in agreement with literature. Larval counts and density of Anopheles mosquitoes are known to be high during rainy seasons and decline during dry seasons [48-50]. This is obviously due to loss of some habitats and decline in mosquito populations during the dry season.

The overall results showed that An. coluzzii declined from March 2013 to February 2014 while the An. gambiae (s.s.) slightly increased within the same period. In AMA, both An. coluzzii and An. gambiae (s.s.) were observed throughout the year and their proportions were higher in the months of April, May, June, October and January. Anopheles gambiae (s.s.) was, however, absent from STMA in the months of May, August, December and January but with higher proportions in the months of April and October. This is similar to what VillarrealTrevino et al. [51] found in Chiapas, Mexico where $A n$. darlingi mosquito was more prevalent in certain months, for example, from June to September and with peaks in July but were less in other months.

Seasonal variations were also observed in the population of Anopheles larvae and larval densities in the study areas, with wet season having both higher larval population and mean larval density compared to the dry season. This suggests that any action to reduce malaria transmission may have to be intensified during the rainy season [52, 53].

Analysis of variance showed that the mean larval densities varied significantly among habitat types with puddles having the highest. Ndenga et al. [54] found puddles to be the most productive larval habitats in Kenya. The high larval density together with the frequency of occurrence accounted for the high contribution of puddles to the total larvae sampled. Similar variations in larval densities were observed in AMA. Apart from streams/rivers which had lowest larval density compared to the rest of the habitat types, no significant differences were found among the rest of the habitat types in STMA. This indicates that whereas some habitats may be more important than others in AMA, almost all habitats in STMA are important in mosquito control. However, it is not clear what accounted for the high productivity of habitats in AMA in terms of larval density compared to STMA. For puddles and urban farm sites in AMA had significantly higher larval densities compared to the same habitats in STMA. The general low larval densities of habitats in STMA might be due to the quality of the water which is being discussed in a subsequent paper. But Kibret et al. [55] also found that some habitats were more important in serving as breeding grounds for Anopheles mosquitoes than others in Ethiopia.

Mean counts of An. coluzzii and An. gambiae (s.s.) also varied significantly among the habitat types in both cities. The similar high counts of An. coluzzii in puddles and urban farm sites in both cities might be due to similar physico-chemical factors prevailing in the habitats. This is also being looked at in our subsequent paper. Similar reasons may account for the high mean count of An. gambiae (s.s.) in AMA compared to STMA. Additionally, puddles and urban farm sites that had higher mean numbers of An. coluzzii compared to the rest of the habitats had the lowest An. gambiae (s.s.) numbers in AMA. In Mali, Edilo et al. [56] observed differences in habitat preference between the two species of $A n$. coluzzii and An. gambiae (s.s.). They found that while An. gambiae (s.s.) together with An. arabiensis exploit the same breeding habitats, An. coluzzii prefer different habitat from the two, though An. coluzzii and An. gambiae (s.s.) were also sympatric.

Regarding spatial distribution, mean larval densities in the two cities showed that puddles (13.7/dip), unpaved drains (12.9/dip) and urban farm sites (11.6/dip) had that highest larval density. However, construction sites, ditches/dugouts and urban farms were the three habitats with high larval densities in STMA whereas puddles, urban farms and construction sites constitute the highest larval habitats in AMA. It is interesting to know that the major contributors to mosquito population in both cities were man-made habitats, supporting the findings of Gimning et al. [57] and Imbahale et al. [30]; and hence suggesting that if we change the way things are done Anopheles population can be drastically reduced.

In AMA puddles and urban farm sites accounted for 63\% of all An. coluzzii found in the city. This preference of An. coluzzii for puddles and urban farm sites is not clear and needs to be investigated. Anopheles gambiae (s.s.) was almost evenly distributed among the habitats in AMA, showing no preference for any habitat. However, $80 \%$ of An. coluzzii found in STMA were almost evenly distributed among nearly all habitats including puddles and urban farm sites which were their preferred habitats in AMA. Anopheles gambiae (s.s.) was generally low in proportion compared to An. coluzzii in all the 
habitats in STMA, however, urban farm sites alone contributed about half (49\%) of all An. gambiae (s.s.) found in the city. This is not only interesting for An. gambiae (s.s.) control but also for An. gambiae (s.s.) larvae collection in STMA. Overall, 70\% of all An. coluzzii sampled in the two cities were found in urban farms, puddles, swamps and ditches/ dugouts whereas, $80 \%$ of all $A n$. gambiae (s.s.) sampled in the two cities were found in drains (paved and unpaved), construction sites, streams/ rivers and "others". In contrast, Edilo et al. [56] did not find any association between the frequencies of larvae of An. coluzzii and An. gambiae (s.s.) among larval breeding habitats.

\section{Conclusions}

In summary, this study reveals the types of Anopheles mosquitoes, their spatio-temporal distribution and preferred habitats in urban areas of southern Ghana. Both larval density and counts were high in wet seasons and more associated with puddles, urban farms and drains. These have prospects for targeted interventions to manage, reduce or eliminate Anopheles breeding habitats. The study also suggests the need for city-dwellers to change their attitude with regard to environmental management. This is because majority of the permanent habitats were man-made and over $60 \%$ of all the habitats encountered were permanent. Proper environmental management is therefore key to curtailing the perennial breeding of Anopheles mosquitoes and for that matter malaria transmission in the two cities.

\section{Additional file}

Additional file 1: a Species identification. Lane 1: ladder; Lane 2: positive; Lanes 3 to 11 and 13 to 21: Anopheles gambiae at 390 bp; Lane 12: Anopheles melas at 464 bp. b PCR-RFLP-molecular identification. Lane 1: ladder; Lanes 2, 3, 5, 9, 11: Anopheles gambiae (s.s.); Lanes 4, 6, 7, 8, 10, 12: Anopheles coluzzii. (TIF $165 \mathrm{~kb})$

\section{Abbreviations}

AMA: Accra metropolitan area; ANOVA: Analysis of variance; EC: Electrical conductivity; SPSS: Statistical package for social sciences; SSA: sub-Saharan Africa; STMA: Sekondi-takoradi metropolitan area

\section{Acknowledgements}

Authors are very grateful to the staff of Parasitology Department of Noguchi Memorial Institute for Medical Research (NMIMR), especially, Mr. Samson Otoo for his immense technical support.

\section{Funding}

Not applicable.

\section{Availability of data and materials}

The datasets analysed during the current study are available from the corresponding author (PADM) on reasonable request.

\section{Authors' contributions}

PADM designed, implemented the project, analysed, interpreted the data and drafted the manuscript. LKA, LB and MDW help in designing the project and revised the manuscript. GF, WDKA and MMM assisted with the analyses, interpretation of the data and drafting of the manuscript. DKdS revised the manuscript. All authors read and approved the final version of the manuscript.

\section{Competing interests}

The authors declare that they have no competing interests.

Consent for publication

Not applicable.

Ethics approval and consent to participate

Not applicable.

\section{Author details}

${ }^{1}$ Institute of Environment and Sanitation Studies (IESS), University of Ghana, Legon, Ghana. ${ }^{2}$ Directorate of Academic Planning and Quality Assurance (DAPQA), University of Cape Coast, Cape Coast, Ghana. ${ }^{3}$ Department of Animal Biology and Conservation Science, University of Ghana, Legon, Ghana. ${ }^{4}$ Department of Physics, Kwame Nkrumah University of Science and Technology, Kumasi, Ghana. ${ }^{5}$ Department of Environment and Development Studies, Central University, Accra, Ghana. ${ }^{6}$ Parasitology Department, Noguchi Memorial Institute of Medical Research, University of Ghana, Legon, Ghana.

Received: 6 August 2016 Accepted: 15 December 2016

Published online: 13 January 2017

References

1. Klinkenberg E, McCall PJ, Hastings IM, Wilson MD, Amerasinghe FP, Donnelly MJ. Malaria and irrigated crops, Accra, Ghana. Emerg Infect Dis. 2005:11:1290-3.

2. Chinery WA. Effects of ecological changes on the malaria vectors Anopheles funestus and the Anopheles gambiae complex of mosquitoes in Accra, Ghana. J Trop Med Hyg. 1984:87(2):75-81.

3. Sattler MA, Mtasiwa D, Kiama M, Prenji Z, Tanner M, Killeen F, Lengeler C. Habitat characterization and spatial distribution of Anopheles sp. mosquito larvae in Dar es Salaam (Tanzania) during an extended dry period. Malar J. 2005:4:4.

4. Bates M. The natural history of mosquitoes. New York: The Macmillan Company; 1949.

5. Muirhead-Thompson RC. Mosquito behavior in relation to malaria transmission and control in the tropics. London: Edward Arnolds \& Co; 1951.

6. Chinery WA. A survey of mosquito breeding in Accra, Ghana during a twoyear period of larval mosquito control: The mosquitoes collected and their breeding places. Ghana Med J. 1969:8:266-74.

7. Keating J, Macintyre K, Mbogo CM, Githure Jl, Beier JC. Characterization of potential larval habitats for Anopheles mosquitoes in relation to urban land-use in Malindi, Kenya. Int J Health Geogr. 2004;3:9.

8. Klinkenberg E, McCall P, Wilson MD, Amerasinghe FP, Donnelly MJ. Impact of urban agriculture on malaria vectors in Accra, Ghana. Malar J. 2008;7:151.

9. Kudom AA, Mensah BA, Agyeman TK. Characterization of mosquito larval habitats and assessment of insecticide-resistance status of Anopheles gambiae sensu lato in urban areas in south western Ghana. J Vector Ecol. 2012;37:77-82

10. Songsore J, Nabila JS, Yanyuoru Y, Amuah E, Bosque-Hamilton EK, Etsibah KK, et al. State of environmental health report of the Greater Accra Metropolitan Area 2001. Accra: Ghana Universities Press; 2005

11. Rakotomanana F, Ratovonjato J, Randremanana RV, Randrianasolo L, Raherinjafy R, Rudant JP, Richard V. Geographical and environmental approaches to urban malaria in Antananarivo (Madagascar). BMC Infect Dis. 2010;10:173

12. MOH. Ghana Maternal Health Survey 2007. Accra: $\mathrm{MOH} ; 2008$.

13. GSS GHS, Macro ICF. Ghana Demographic and Health Survey 2008. GSS: Accra; 2009

14. NDPC/GoG,UNDP. 2008 Ghana Millennium Goals Report. Ghana: NDPC/GoG; 2010.

15. Biritwum RB, Welbeck J, Barnish G. Incidence and management of malaria in two communities of different socio-economic level, in Accra, Ghana. Ann Trop Med Parasitol. 2000:94(8):771-8.

16. Taylor P, Boussen CR, Awunyo-Akaba J, Nelson J. Ghana, Urban Health Assessment. Environ Health Proj Activ Rep. 114;1-89.

17. Dickson KB, Benneh G. A New Geography of Ghana. London: Longman; 1988. 
18. Service MW. Mosquito Ecology: Field Sampling Methods. 2nd ed. London: Elsevier Science; 1993.

19. Malaria Research and Reference Reagents Resource (MR4). Methods in Anopheles Research. Atlanta: CDC, NIH, ATCC; 2007.

20. Gillies MT, De Meillon B. The Anophelinae of Africa south of the Sahara (Ethiopian Zoogeographical Region). Publ S Afr Inst Med Res. 1968:54:1-343.

21. Gillies MT, Coetze M. A Supplement to Anophelinae of Africa South of the Sahara (Afrotropical Region). Publ S Afr Inst Med Res. 1987;55:1-146.

22. Walsh PS, Metzger DA, Higuchi R. Chelex 100 as a medium for simple extraction of DNA for PCR-based typing from forensic material. BioTech. 1991;10:506-13.

23. Scott JA, Brogdon WG, Collins FH. Identification of single specimens of the Anopheles gambiae complex by the polymerase chain reaction. Am J Trop Med Hyg. 1993;49:520-9.

24. Fanello C, Santollamazza F, della Torre A. Simultaneous identification of species of and molecular forms of Anopheles gambiae complex by PCR-RFLP. Med Vet Entomol. 2002;16:461-4.

25. McCall PJ, Cameron MM. Oviposition pheromones in insect vectors. Parasitol Today. 1995;11:352-5

26. Sumba LA, Ogbunugafor CB, Deng AL, Hassanali A. Regulation of oviposition in Anopheles gambiae s.s.: role of inter- and intra-specific signals. J Chem Ecol. 2008;34:1430-6.

27. Himeidan YE, Temu EA, El Rayah EA, Munga S, Kweka EJ. Chemical cues for malaria vectors oviposition site selection: challenges and opportunities. J Insects. 2013;2013:685182.

28. Keating J, Maclntyre K, Mbogo C, Githeko A, Regens JL, Swalm C, et al. A geographic sampling strategy for studying relationships between human activity and malaria vectors in urban Africa. Am J Trop Med Hyg. 2003;68: 357-65.

29. De Silva PM, Marshall JM. Factors contributing to urban malaria transmission in sub-Saharan Africa: A systematic review. J Trop Med. 2012;2012:819563.

30. Imbahale SS, Paaijmans KP, Mukabana WR, Lammeren R, Githeko AK, Takken W. A longitudinal study on Anopheles mosquito larval abundance in distinct geographical and environmental settings in western Kenya. Malar J. 2011;10:81.

31. Mereta ST, Yewhalaw D, Boets P, Ahmed A, Duchateau L, Speybroeck N, et al. Physico- chemical and biological characterization of anopheline mosquito larval habitats (Diptera: Culicidae): implications for malaria control. Parasit Vectors. 2013:6:320

32. EHG. Evaluation of the Malaria Programme funded by the Global Fund in Ghana (2003-2011) Final Draft Evaluation Report, Commissioned by The Global Fund to Fight AIDS, Tuberculosis and Malaria; 2011. Cited from https://www.ghanahealthservice.org/downloads/Evaluation_of_malaria_ programme_funded_by_global_fund.pdf. Accessed on 26 July 2015.

33. Khaemba BM, Mutani A, Bett MK. Studies of anopheline mosquitoes transmitting malaria in a newly developed highland urban area: a case study of Moi University and its environs. East Afr Med J. 2012;71:159-64.

34. Tyagi BK. Urban malaria on the Indian sub-continent. In: Klinkenberg $E_{\text {, }}$ Donnelly M, McCall PJ, editors, Urban malaria in Africa. Proceedings of a technical consultation on the strategy for assessment and control of urban malaria, Pretoria, South Africa. 02-05 December, 2004. Colombo, Sri Lanka, International Water Management Institute (IWMI); 2005.

35. De Castro MC, Yamagata Y, Mtasiwa D, Tanner M, Utzinger J, Keiser J, Singer BH. Integrated urban malaria control: a case study in Dar es Salaam, Tanzania. Am J Trop Med Hyg. 2004;71 Suppl 2:103-17.

36. Dery DB, Brown C, Asante KP, Adams M, Dosoo D, Amenga-Etego S, et al. Patterns and seasonality of malaria transmission in the forest-savannah transitional zones of Ghana. Malar J. 2010:9:314.

37. Ajayi MB, Adeleke MA, Idowu ET, Awolola TS. Surveillance of mosquitoes vectors in Ajumoni Estate Ogun State, Nigeria. Ann Biol Res. 2010;1(4):16-9.

38. Tuno N, Kjaerandsen J, Badu K, Kruppa T. Blood-feeding behavior of Anopheles gambiae and Anopheles melas in Ghana, Western Africa. J Med Entomol. 2010;47(1):28-31.

39. de Souza D, Kelly-Hope L, Lawson B, Wilson M, Boakye D. Environmental factors associated with the distribution of Anopheles gambiae s.s in Ghana; an important vector of lymphatic filariasis and malaria. PLoS One. 2010;5(3):e9927.

40. Kabula Bl, Attah PK, Wilson MD, Boakye DA. Characterization of Anopheles gambiae s.l. and insecticide resistance profile relative to physicochemical properties of breeding habitats within Accra Metropolis, Ghana. Tanz J Health Res. 2011;13:3.
41. Coetzee M, Craig M, Le Sueur D. Distribution of African malaria mosquitoes belonging to the Anopheles gambiae Complex. Parasitol Today. 2000;16:74-7.

42. Gentile G, della Torre A, Maegga B, Powell JR, Caccone A. Genetic differentiation in the African malaria vector, Anopheles gambiae s.s. Genetics. 2002;161(4):1561-78.

43. della Torre A, Tu Z, Petrarca V. On the distribution and genetic differentiation of Anopheles gambiae s.s. molecular forms. Insect Bio Mol Bio. 2005;35:755-69.

44. de Souza DK, Koudou BG, Bolay FK, Boakye DA, Bockarie MJ. Filling the Gap 115 Years after Ronald Ross: The distribution of the Anopheles coluzzii and Anopheles gambiae s.s from Freetown and Monrovia, West Africa. PLoS One. 2013;8(5):e64939.

45. Hunt RH, Fuseini G, Knowles S, Stiles-Ocran J, Verster R, Kaiser ML, et al. Insecticide resistance in malaria vector mosquitoes at four localities in Ghana, West Africa. Parasit Vectors. 2011;4:107.

46. Achonduh OA, Gbewonyo WSK, Boakye DA, Wilson MD. Susceptibility status of Anopheles gambiae s.l. (Diptera: Culicidae) from cabbage growing areas associated with pyrethroid and organophosphate use in Accra, Ghana. West Afr J Appl Ecol. 2008;12:1-12.

47. Clarkson CS, Weetman D, Essandoh J, Yawson AE, Maslen G, Manske M, et al. Adaptive introgression between Anopheles sibling species eliminates a major genomic island but not reproductive isolation. Nat Commun. 2014;5:4248.

48. Lamidi TB. Distribution and seasonal abundance of anopheline mosquito species in Nguru, Yobe state, North-Eastern Nigeria. Anim Res Int. 2009:6(1):949-52.

49. Oyewole V, Ibidapo CA, Okwa OO, Oduola AO, Adeoye GO, Okoh HI, Awolola TS. Species composition and role of Anopheles mosquitoes in malaria transmission along Badagry axis of Lagos lagoon, Lagos, Nigeria. Int J Insect Sci. 2010;2:51-7.

50. Donovan C, Siadat B, Fimpong J. Seasonal and socio-economic variations in clinical and self-reported malaria in Accra, Ghana: evidence from facility data and a community survey. Ghana Med J. 2012;46(2):85-94.

51. Villarreal-Trevino C, Penilla-Navarro RP, Vázquez-Martínez MG, Moo-Llanes DA, Rios-Delgado JC, Fernandez-Salas F, Rodriguez AD. Larval habitat characterization of Anopheles darlingi from its northernmost geographical distribution in Chiapas, Mexico. Malar J. 2015;14:517.

52. Fillinger $U$, Lindsay SW. Suppression of exposure to malaria vectors by an order of magnitude using microbial larvicides in rural Kenya. Trop Med Int Health. 2006;11:1629-42.

53. Mala AO, Irungu LW, Shililu JI, Muturi EJ, Mbogo CC, Njagi JK, Githure Jl. Dry season ecology of Anopheles gambiae complex mosquitoes at larval habitats in two traditionally semi-arid villages in Baringo, Kenya. Parasit Vectors. 2011:4:25.

54. Ndenga BA, Simbauni JA, Mbugi JP, Githeko AK, Fillinger U. Productivity of malaria vectors from different habitat types in the western Kenya Highlands. PLoS One. 2011;6(4):e19473.

55. Kibret $\mathrm{S}$, Petros B, Boelee $\mathrm{E}$, Tekie $\mathrm{H}$. Entomological studies on the impact of a small-scale irrigation scheme on malaria transmission around Ziway, Ethiopia. In: Awulachew SB, Loulseged M, Yilma AD, editors. Impact of irrigation on poverty and environment in Ethiopia: draft proceedings of the symposium and exhibition, Addis Ababa, Ethiopia, 27-29 November 2007. Colombo: International Water Management Institute (IWMI); 2008. p. 418-38.

56. Edillo FE, Tripet F, Toure YT, Lanzaro GC, Dolo G, Taylor CE. Water quality and immatures of the $\mathrm{M}$ and $\mathrm{S}$ forms of Anopheles gambiae s.s. and An. arabiensis in a Malian village. Malar J. 2006:5:1-10.

57. Gimning JE, Ombok M, Otieno S, Kaufman MG, Vulule JM, Walker ED. Density-dependent development of Anopheles gambiae (Diptera: Culicidae) larvae in artificial habitats. J Med Ent. 2002;29:162-72. 